\title{
TWELFTH INTERNATIONAL RADIOCARBON CONFERENCE AFTER DINNER REMARKS
}

\author{
PAUL E DAMON \\ Department of Geosciences, University of Arizona \\ Tucson, Arizona 85721
}

The 12th International Radiocarbon Conference has been a success! To paraphrase Francis Bacon's words in his treatise, "The Novuum Organum," we have gathered together as true sons and daughters of knowledge "to overcome not an adversary in argument but nature in action"; and we have enjoyed good fellowship in the process. I feel strongly in a conference such as this that we, in our science, are a great international fraternity joined together as comrades for unselfish cooperation in research, which is the motto of the American Geophysical Union.

We have come a long way since Libby first detected ${ }^{14} \mathrm{C}$ in gas from the sewers of Baltimore and our journey has carried us to Kepler's fiery God, the sun, which it now seems increasingly certain not only produces climate but modulates climate to the same temporal tune that it modulates ${ }^{14} \mathrm{C}$. It might be said that our work has carried us from the slime to the sublime from the sewers of Baltimore to the stars whose catastrophic death spasms, as super novae, may yet be recovered from the terrestrial radiocarbon record.

As scientists, we are not afraid to dirty our hands, to dig in the soil and handle old bones and animal dung because, as Bacon said, "the sun light enters the sewer as well as the King's Palace and is not contaminated by either." It has been said that there are very few scatologists in the world and they are all at the University of Arizona.

Our work has touched on many fields: physics, astronomy, chemistry, geology, geochemistry, geophysics, meteorology, pedology, climatology, dendrochronology, biology, forestry, glaciology, hydrology, environmental science, and archaeology. These divisions are a matter of convenience. As Professor Rafter said in his remarks at the 8th International Radiocarbon conference in New Zealand, "Nature is one piece, like a seamless garment."

Our work has provided the fourth dimension of time to even out the Cartesian coordinates, and in doing so has produced revolutions in archaeology. According to Renfrew, the first revolution occurred when radiocarbon proved the great antiquity of the European and Near East Neolithic period, setting its beginning some 3000 years earlier than previously hypothesized with the traditional short chronology. The second revolution occurred when radiocarbon refined by calibration against dendrochronology indicated that European cultures did not postdate the Middle Eastern cultures as the diffussionists expected.

We have seen an evolution in counting techniques from the screen wall counter, to the proportional counter and the scintillation counter which has not plateaued out on the sigma curve. This has been followed by a technical revolution with the advent of accelerator mass spectrometry reducing 
sample size from grams to milligrams and introducing other cosmogenic isotopes as clocks and tracers. Pioneers have shown us the importance of high-precision counting providing an increasingly refined time scale and, as retrospective environmental monitors, opening up new prospects of revolutions in magnetic field theory, solar physics, and climatology.

As Hans Suess pointed out in the opening session, what at first appeared as erroneous ages resulting from a flaw in the basic assumptions of radiocarbon dating has become a study of the variations of post-atmospheric ${ }^{14} \mathrm{C}$ concentrations, with ramifications at least as far-reaching as the radiocarbon method itself. Historical records of "blemishes" on the sun, vacillation of magnetic fields, agricultural and industrial expansion, and instruments of war have all contributed to changes in cosmogenic isotope abundances and, in turn, these and other phenomena have yielded valuable information about themselves.

Speaking of weapons of war, it is said that "a prophet is not without honor except in his own land." I suppose that Dr Nydal and the Trondheim team are best known in Norway for their radiocarbon dating, but I suspect that their countrymen do not know them as pioneers who recognized that radiocarbon from that terrible weapon, the atomic bomb, could be used as a tracer to follow carbon in its journey throughout the cycle and to time its rate of transfer from one reservoir to another much as a medical doctor uses isotopes as tracers from one organ to another of the human body. The Trondheim group may be best known in Norway for radiocarbon dating but they are best known internationally for Dr Nydal's pioneering thesis and subsequent follow-up with the Trondheim team.

Yes, the conference has been a success and, I trust, will continue on its successful course, thanks to the good work of the organizing committee, Reidar Nydal, Chairman, Steinar Gulliksen, Per Christian Hammer, Sverre Westin, and the Secretariat, Pat Ueland, Arne Fredlund, and Natalia Ueland, not mentioning by name other unsung laborers in the radiocarbon vineyard. Let's give them all a big round of applause! 